\title{
Comentário
}

\section{Breve nota histórica}

O presente trabalho, coordenado por Ronaldo Laranjeira, que bem soube liderar um expressivo grupo de colegas brasileiros, todos profissionais experientes no tratamento de pacientes alcoolistas, é o resultado mais recente de um esforço de três décadas.

Já nos idos dos anos 70, tive a honra, juntamente com Jandira Masur, José Manoel Bertolote e Vicente Antônio Araújo, de fazer parte do grupo pioneiro de lideranças na área da pesquisa e tratamento do dependente químico no país. A essas somaram-se Arthur Guerra de Andrade, Dagoberto Hungria Requião, Ernani Luz Jr. e Ângelo Campana, entre outros. Desde então criou-se um movimento que se organizou primeiramente em torno do GRINEAA (Grupo Interdisciplinar de Estudos do Álcool e do Alcoolismo), depois ABEAA (Associação Brasileira de Estudos do Álcool e do Alcoolismo), e mais recentemente ABEAD (Associação Brasileira de Estudos do Álcool e outras Drogas), associação que desde sua fundação vê em sua contribuição social um de seus imperativos estatutários.

Mais recentemente, esse mesmo grupo, agora já bastante numeroso, teve condições de fundar o Departamento de De- pendência Química da ABP, contando, para isso, com os valiosos apoios de Rogério Aguiar e Miguel Roberto Jorge.

O presente "consenso", portanto, é apenas o documento mais atual produzido por esse movimento, numa iniciativa de nosso Departamento, que contou também com a contribuição da ABEAD. A primeira dessas contribuições foi o PRONAL (Programa Nacional de Alcoolismo), de 1978. A ela se seguiram várias outras, a última datando do início dos anos 90, o Programa Valorização da Vida, de prevenção do consumo de drogas em escolas. Desde então parece não ter havido condições para que a saúde pública avançasse na questão da dependência química.

Esse "consenso", que haverá de ser o primeiro de vários, marca a retomada de uma contribuição à qual nós especialistas nos impomos. Espero apenas que seja útil e represente uma contribuição consistente.

Sérgio de Paula Ramos

Coordenador do Departamento de Dependência Química da ABP 